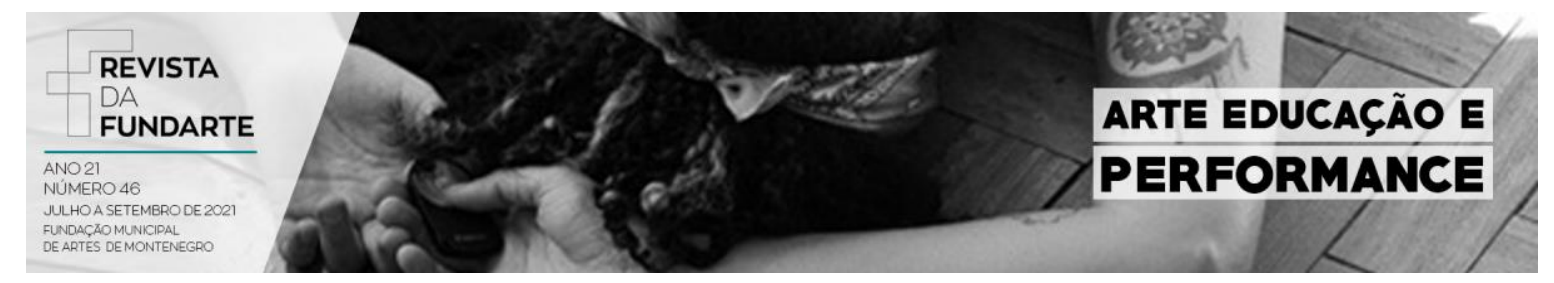

\title{
DANÇAS POSSÍVEIS EM TEMPOS DE PANDEMIA
}

\author{
Neila Cristina Baldi \\ Samara Weber Schmidt
}

DOI: http://dx.doi.org/10.19179\%2F2319-0868.860 


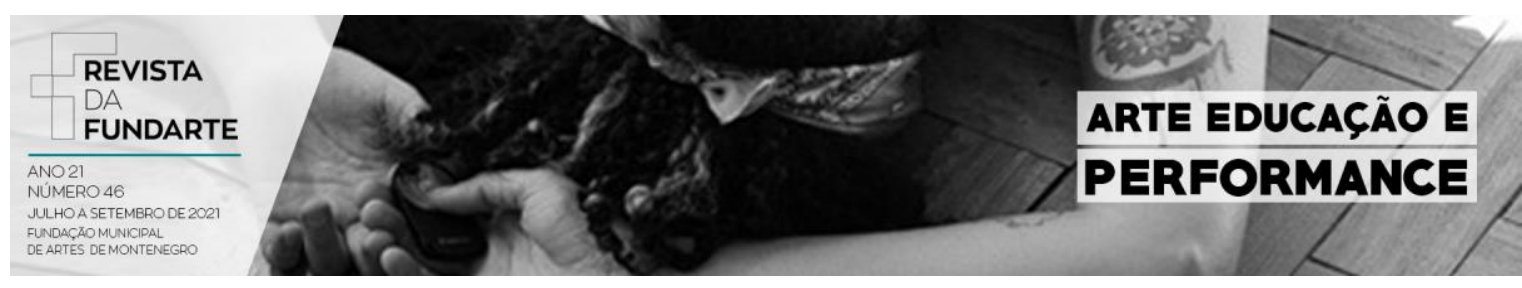

\title{
DANÇAS POSSÍVEIS EM TEMPOS DE PANDEMIA
}

\author{
Neila Cristina Baldi ${ }^{1}$ \\ Samara Weber Schmidt ${ }^{2}$
}

\begin{abstract}
Resumo: Este texto discute ações do projeto de extensão 5, 6, 7 e 8 - cursos e oficinas de Dança, do Curso de Dança-Licenciatura da Universidade Federal de Santa Maria (UFSM) durante o período de isolamento social provocado pela pandemia da Covid-19. Entre agosto e dezembro de 2020 foram desenvolvidas três ações on-line, duas em uma escola pública de Santa Maria: Crian(dan)ça, com crianças do ensino fundamental, e (Edu)Dançando na Escola, curso de formação continuada para professores(as). Paralelamente ocorreram as lives 5 e 6 , que discutiram temas como Dança com Crianças e Educação Antirracista e Dança. O texto reflete sobre as dificuldades e desafios do ensino remoto e os benefícios da formação em Dança para profissionais da educação básica.
\end{abstract}

Palavras-chave: Dança; Ensino Remoto; Pandemia.

\section{POSSIBLE DANCES IN PANDEMIC TIMES}

\begin{abstract}
This text discusses actions of the extension project 5, 6, 7 and 8 -Dance courses and workshops -, present in UFSM's (Federal University of Santa Maria) Dance degree program, during the period of social isolation caused by the Covid-19 pandemic. Between August and December 2020, three online actions were developed, two in a public school in Santa Maria: Crian(dan)ça, with elementary school children, and (Edu)Dançando na Escola, continuing education course for teachers. In parallel, livestreams 5 and 6 happened, discussing topics such as Dance with Children and Anti-
\end{abstract}

\footnotetext{
${ }^{1}$ Doutora em Artes Cênicas pelo PPGAC/UFBA. Mestra pelo mesmo programa. Professora Adjunta do Curso de Licenciatura em Dança da Universidade Federal de Santa Maria (UFSM). Especialista em Dança em Consciência Corporal pela UniFMU (2007), em Gestão Cultural pelo Senac (2013) e em Sistema Laban/Bartenieff (2021). Possui graduação em Dança pela Universidade Anhembi Morumbi (2009) - licenciatura e bacharelado - e graduação em Comunicação Social pela Universidade Federal do Rio Grande do Sul (1999). Foi professora da educação básica nas séries iniciais (Magistério) e professora de dança na educação básica (infantil e fundamental I). Foi jornalista por 16 anos, atuando nos estados do RS, SP e DF, em veículos impressos e órgãos de governo. Atualmente pesquisa pedagogias da dança, educação somática, autobiografia, decolonialidade e balé clássico. Coordena o Programa Institucional de Bolsas de Iniciação à Docência (PIBID-Dança) e o Curso de Dança-Licenciatura. É membro do Conselho de Ensino, Pesquisa e Extensão da UFSM (CEPE) e da Comissão de Legislação e Normas (CLN) do mesmo. Suplente da Conselho editorial da Editora da UFSM.

${ }^{2}$ Tem experiência na área de Artes, com ênfase em Dança, atuando principalmente nos seguintes temas: processo de criação, ensino da dança e dança. Atualmente é participante do Laboratório Investigativo de Criações Contemporâneas em Dança (LICCDA), intérprete-criadora da Crystian Castro Companhia de Dança, e artista-docente ministrando aulas de dança síncronas e assíncronas. Estudante do Curso de Dança-Licenciatura da UFSM, Bolsista FIEX.
}

BALDI, Neila Cristina; SCHMIDT, Samara Weber. Danças possíveis em tempos de pandemia. Revista da FUNDARTE. Montenegro, p.01-16, ano 18, oㅜ 46, setembro de 2021.

Disponível em: http://seer.fundarte.rs.gov.br/index.php/RevistadaFundarte/issue/archive $>30$ de setembro de 2021. 


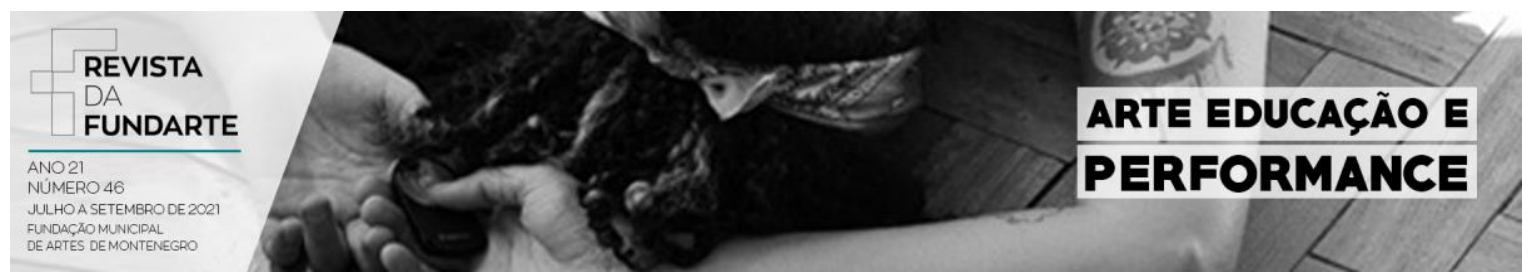

Racist Education and Dance. This text reflects on the difficulties and challenges of remote teaching and the benefits of dance training for basic education professionals.

Keywords: Dance; Remote Teaching; Pandemic.

A pandemia da Covid-19 fez com que as experiências artísticas e de educação de Artes se modificassem. No entanto, no caso da Dança, a relação com a tecnologia não é dos tempos atuais. A depender de como se pensa e se conceitua tecnologia, há quem compreenda o uso de cenários mecanizados e da iluminação a gás, em La Sylphide, como a primeira relação da Dança com a tecnologia. No entanto, segundo Barbosa (2016, p. 33): "Ao que parece, foi com a obra Serpentines Dances (1891) de Loïe Fuller (1862-1928), que a tecnologia passa de ferramenta ao elemento estético fundante para a obra." O desenvolvimento de pesquisas nos leva, ao final do século passado, à dança telemática - que se utiliza de tecnologias digitais e da internet.

Chegamos a 2020 com muito desenvolvimento na área da dança e tecnologias, com profissionais se dedicando à pesquisa estética nessa área. No entanto, a tecnologia não é acessível a todas as pessoas e, com a pandemia da Covid-19 e a necessidade de isolamento social há uma verdadeira corrida para o online sem, necessariamente, preparo. Portanto, muito do que foi produzido no ano passado, na área da dança, ainda é uma investigação e, não necessariamente, se relaciona com as pesquisas que vinham sendo feitas relativas à Dança e tecnologias - dança telemática ou videodanças, por exemplo.

Como afirma Santana (2006, p. 101):

Os artistas sempre se utilizaram da tecnologia vigente em cada época, portanto não há um privilégio atual para este tipo de relação. A diferença estará na condição da tecnologia existente e no tipo de relacionamento estabelecido com ela.

Em 2020, em alguma medida, todos(as) nós, que vivíamos a Dança de forma presencial, passamos para o remoto, e produzimos outras danças possíveis, no 


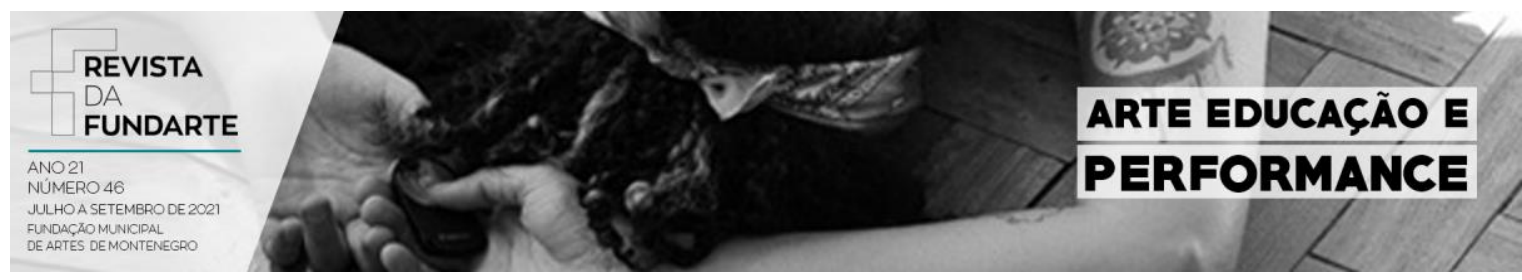

contexto da pandemia da Covid-19. Nicolini (2020, p. 296) nos lembra que: "A arte, em especial a dança, precisa do encontro físico, dos desdobramentos sensóriomotores geradores de afetos e emoções. Tudo isto está na base da pirâmide alimentar da dança, ou das muitas danças." Como mantemos estes afetos no remoto? Que presenças são possíveis no remoto? Que danças estamos produzindo no remoto? Temos usado o termo dança entre-telas para conceituarmos o que estamos vivendo. É uma dança que se dá em casa, com o uso de tecnologias digitais, que é vista e vivida por entre-telas - do celular, do computador -, mas que não produz danças 'manipulando' as tecnologias - como numa dança telemática ou na videodança. Trata-se de usar a tecnologia para se conectar com o(a) outro(a) e dançar junto, de alguma forma.

Neste texto discutimos três ações do projeto de extensão 5,6,7 e 8 - cursos e oficinas de Dança, do Curso de Dança-Licenciatura da Universidade Federal de Santa Maria (UFSM), realizadas em 2020, a partir do ensino remoto: Crian(dan)ça, com crianças do ensino fundamental; (Edu)Dançando na Escola, curso de formação continuada para professores(as); e as lives 5 e 6 , destinadas a profissionais da Dança ou da Educação, que discutiram temas como Dança com Crianças e Educação Antirracista e Dança. Assim, a depender da ação desenvolvida, temos usado tecnologias diferenciadas.

Para o Crian(dan)ça foram criados vídeos curtos - de dois a três minutos cada - que podiam ser vistos no Youtube ou pelo Whatsapp, uma vez que eram enviados para o grupo das turmas. Paralelamente, as crianças recebiam semanalmente das escolas polígrafos com atividades e os vídeos de dança estavam descritos nestes polígrafos. Uma outra opção, ao final do projeto, foi o envio de mensagens de voz com a atividade. Para as professoras, na ação (Edu)Dançando na Escola, a tecnologia utilizada foi a de encontros síncronos, via Google Meeting. $\mathrm{E}$, por fim, as lives 5 e 6 - abertas a um público variado - eram desenvolvidas no Instagram e se davam com conversas com um(a) profissional da Dança falando de suas ações e metodologias, bem como as adaptações para o momento remoto. 


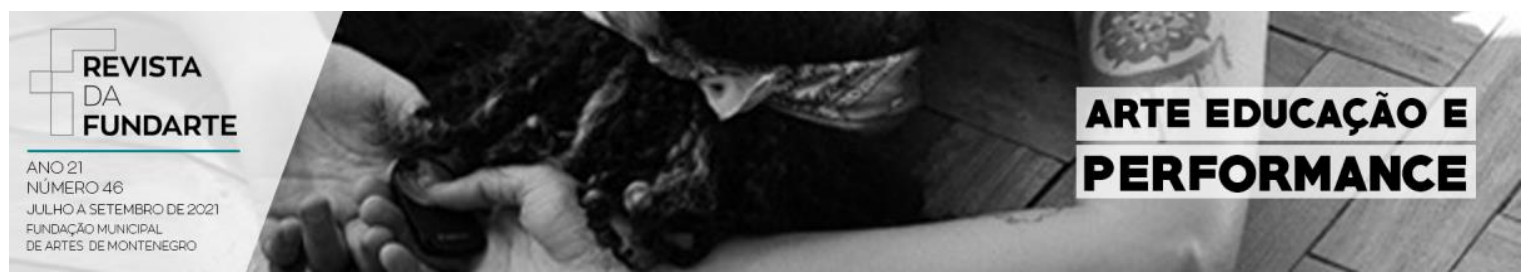

O projeto de extensão 5,6,7 e 8 - cursos e oficinas de Dança, do Curso de Dança-Licenciatura da Universidade Federal de Santa Maria (UFSM), foi criado em 2017 e sempre desenvolveu suas ações de forma presencial, nas dependências da Universidade, em ONGs ou escolas. No ano de 2020 foi a primeira vez que o projeto obteve recursos do Fundo de Incentivo de Extensão (FIEX), o que possibilitou ter uma bolsista para o desenvolvimento das ações. Com a pandemia da Covid-19, o planejamento para 2020, que previa oficinas para crianças e formação continuada de professores(as) em uma escola pública, precisaram ser revistas e adiadas, iniciando-se apenas em agosto do ano passado. Por outro lado, o uso das tecnologias digitais também possibilitou a criação de uma terceira ação: as lives $5 \mathrm{e}$ 6 , que ocorreram em outubro e novembro de 2020 , com a presença de profissionais de diversas localidades do país.

Desta forma, o projeto foi desenvolvido no período de agosto a dezembro de 2020. A primeira ação, iniciada em agosto, foi Crian(dan)ça, realizada com duas turmas do ensino fundamental da Escola Municipal Renato Zimmermann - crianças entre seis e nove anos, do primeiro e segundo anos. Paralelamente, a partir do final de setembro, foi realizada a ação (Edu)Dançando na Escola, curso de formação continuada para professores(as) da educação infantil e fundamental com profissionais da mesma escola. Outra ação foi o desenvolvimento das lives 5 e 6, que discutiram temas como Dança com Crianças e Educação Antirracista e Dança, nos meses de outubro e novembro de 2020. Ests eram direcionadas a profissionais da Dança ou da Educação de forma geral e ficaram gravadas no Instagram do Curso de Dança-Licenciatura, podendo ser acessadas a qualquer momento.

\section{Ensino Remoto}

Para discutir as ações de Dança e educação do ano passado, precisamos, necessariamente, falar em ensino remoto. No Brasil, diante das desigualdades econômicas e sociais, os modelos de remoto variam conforme as condições das 


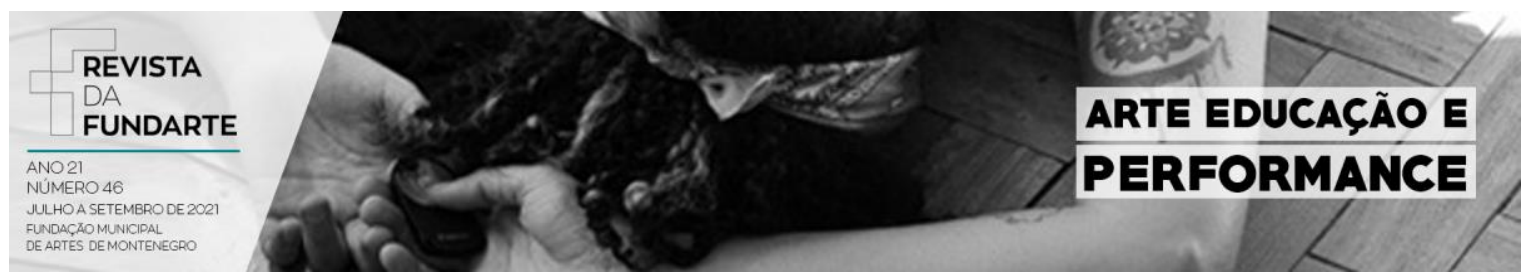

pessoas. A pandemia da Covid-19, que escancarou todas as nossas desigualdades sociais, também nos deixou dar à vista às dificuldades de acesso a tecnologias. $E$ não foi diferente na cidade de Santa Maria, onde as ações do projeto de extensão $5,6,7$ e 8 foram desenvolvidas.

Temos, nos últimos anos, um bombardeio de tecnologias, são aplicativos, sites, modelos de celulares e TVs diversos, que nos permitem - se quisermos estar conectados(as) o tempo todo. No entanto, os melhores aparelhos e as melhores bandas de internet estão concentradas em pessoas com mais poder econômico. Assim ocorre também nas redes de ensino. Segundo Rachel, Marques e Mariano (2020, p. 17):

Se, por um lado, tal adensamento da invasão das tecnologias digitais nas nossas vidas cotidianas promete acentuar o que tem sido chamado de teledependência (BAITELLO JR., 2012), a qual alguns professores e estudantes já estavam submetidos, por outro lado é igualmente importante lembrar que a imensa maioria dos estudantes da rede de ensino básica pública brasileira sequer dispõe do privilégio de alguma forma de aparição nas telas. De modo que podemos falar em povos desaparecidos entre os pixels e bits do excesso das atividades escolares remotas - principalmente, no que diz respeito à população indígena, preta, parda e pobre no Brasil, segundo um levantamento de dados feito pelo Centro Brasileiro de Análise e Planejamento (CEBRAP) em pareceria com a Rede de Pesquisa Solidária, com base nas informações da Pnad-Covid do IBGE.

A emergência da pandemia da Covid-19 e o fechamento das atividades consideradas não essenciais fez com que as redes de ensino tivessem que se adaptar ao remoto.

Professores(as) e estudantes ficaram em casa e, a depender da rede, por tempos diferenciados. No caso da UFSM, o ano letivo havia iniciado na semana em que a pandemia foi decretada e no dia 17 de março de 2020 já havia Instrução Normativa com a proposição do Regime de Exercícios Domiciliares Especiais (REDE), visando a manutenção de vínculos, inicialmente. No decorrer do semestre, a ênfase passou a ser os conteúdos das disciplinas, com aulas síncronas e assíncronas. Importante ressaltar que o regime foi implantado mesmo sem se ter a real dimensão de quantos(as) estudantes teriam disponibilidade de realizar aulas da FUNDARTE. Montenegro, p.01-16, ano 18, no 46, setembro de 2021.

Disponível em: http://seer.fundarte.rs.gov.br/index.php/RevistadaFundarte/issue/archive $>30$ de setembro de 2021. 


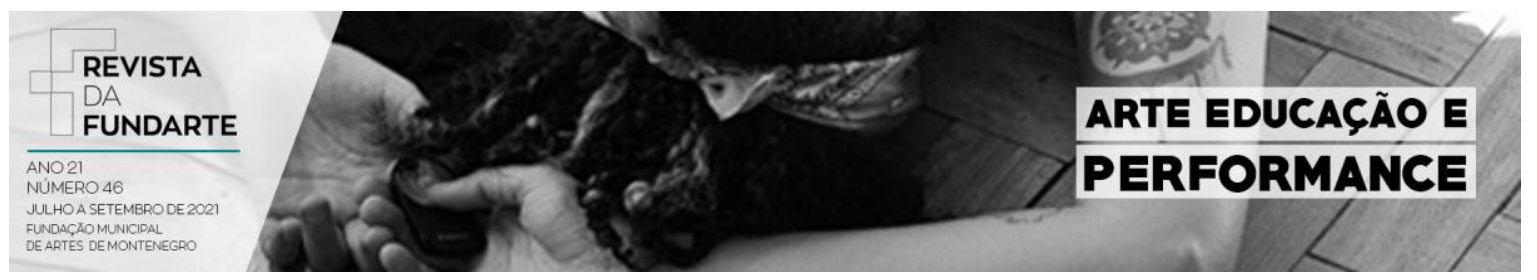

remotamente, assim como não houve treinamento dos(as) professores(as) - os cursos de qualificação docente só começaram em junho.

É por isso que muitos(as) pesquisadores(as) têm insistido na diferença da educação à distância e do que vivemos, atualmente, em casa, por causa da pandemia, como explica Flores (2020, s.n.):

A Educação à Distância é diferente do que temos neste momento, pois preveria um planejamento anterior, com treinamento adequado e estrutura escolar e dos estudantes. O que temos neste momento poderia ser chamado de ensino remoto emergencial. E aí uma das questões é qual a condição desta educação mediada por tecnologias para que todos fiquem em casa enquanto durar a pandemia aconteça no Brasil?

Segundo dados do IBGE, citados pela pesquisadora, 43,4\% dos domicílios brasileiros possuíam computadores pessoais e 13,7\% tablets, em 2017, enquanto 0 celular estava presente em $93,2 \%$ dos domicílios. É a realidade que vemos, também, entre os(as) estudantes da rede pública onde desenvolvemos nosso projeto de extensão.

No caso da rede municipal de Santa Maria, o ano letivo havia iniciado em fevereiro e cada escola teve, inicialmente, a sua dinâmica própria, quando foi decretada a quarentena, na segunda quinzena de março. Na EMEF Renato Zimmermann, entre final de março e maio, as equipes mantinham contato com as crianças primeiro pelo Facebook, depois por grupos de WhatsApp. A escola está localizada no mesmo bairro que a UFSM: Camobi, que tem atualmente pouco mais de 20 mil habitantes e é bastante heterogêneo. A porção norte do bairro, ao longo da ferrovia, é o núcleo de povoamento inicial de Camobi e hoje há loteamentos de classe baixa e ocupações irregulares, como é o caso da Vila Jardim, onde está localizada a escola. Do lado oposto, atravessando duas BRs, está a UFSM e, no seu entorno, edifícios e pessoas de classe média.

Os(as) estudantes da EMEF Renato Zimmermann são, na sua maioria, dos arredores da escola ou de um loteamento popular denominado Cohab Fernando 


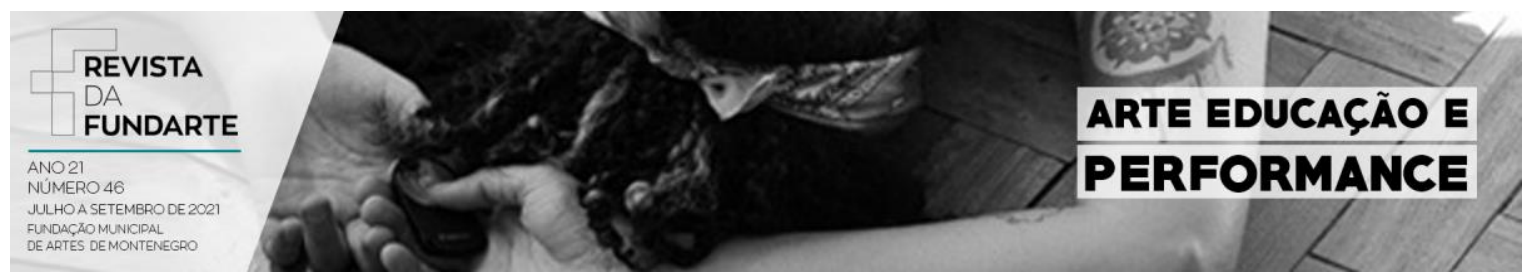

Ferrari, que fica próximo à Universidade. Cabe ressaltar que, segundo Spode et al (2019), na Vila Jardim os esgotos domésticos são lançados a céu aberto, em sarjetas ou valas; e os problemas com relação ao saneamento básico são históricos no bairro, principalmente na porção norte e na Cohab Fernando Ferrari. Vivendo nestas condições socioeconômicas difíceis, é de se ter consciência que há problemas também em relação à internet - a maioria usa dados móveis de celulares. Por sua vez, os familiares têm pouca instrução, poucos possuem ensino médio.

Diante desta precariedade, a escola optou, a partir de junho, pelo ensino remoto por meio de polígrafos semanais, que são retirados pelos pais e mães em um dia da semana estipulado. Dúvidas são sanadas neste dia ou pelo grupo de Whatsapp. Por parte do projeto de extensão, as atividades começaram no final de agosto, por meio do envio de vídeo no Youtube e WhatsApp e impressas junto com as demais da semana.

Por outro lado, o trabalho com as professoras, que começou em setembro, se dava em encontros quinzenais, on-line, síncronos, pelo Google Meeting, uma vez que a realidade delas era diferente da dos(as) estudantes. Já a outra ação do projeto, as lives 5 e 6 ocorreram semanalmente, entre outubro e novembro, pelo Instagram e eram abertas às professoras da comunidade escolar trabalhada, mas também à comunidade em geral - inclusive estudantes do Curso de DançaLicenciatura - e, além de ocorrerem ao vivo, com possibilidade de interação no momento, ficaram gravadas no perfil do curso, o que faz com que possam ser acessadas a qualquer momento.

\section{Possibilidades de dança}

Tanto com as crianças quanto com as professoras, nosso intuito era dar protagonismo às suas danças, o que significava não levar fórmulas prontasrepertórios dançados - mas propor investigações de movimento. Por isso, nossa ação foi pautada na metodologia Dança no Contexto (MARQUES, 2010) 


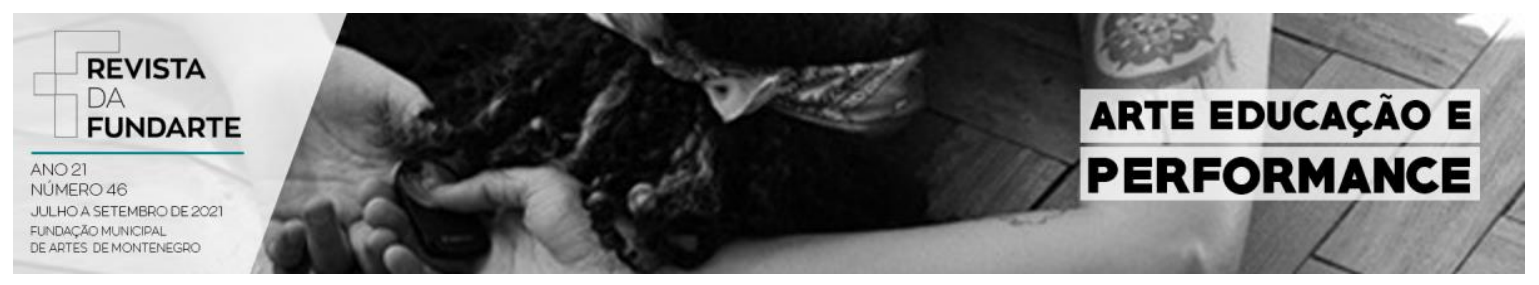

Com o ensino remoto, nosso primeiro desafio era transpor o projeto para o on-line sem descaracterizar nossa proposta pedagógica. Tínhamos um duplo desafio: o acesso às atividades - uma vez que, por causa da baixa conectividade das famílias não há a possibilidade de aulas síncronas, no caso das crianças, - e a manutenção de uma proposta de aprendizagem por meio da investigação no remoto. A metodologia Dança no Contexto propõe relações entre dança, ensino e sociedade em uma quadra de princípios articuladores: problematização, articulação, crítica e transformação. De acordo com Marques (2010), a problematização diz respeito ao indagar, perguntar, propor, questionar; enquanto a articulação refere-se à conexão consigo e com o mundo, inclusive articulando a rede de saberes em dança e com dança. Por sua vez, o criticar é o distanciar-se, ver com outros olhos; e a transformação diz respeito às possibilidades de reconfiguração. A partir dessas premissas, iniciamos as duas ações, primeiro com as crianças, depois, com as professoras.

Com as crianças, tentamos fazer um diagnóstico das turmas, por meio de questões às professoras. Desta forma, levantamos questões que achávamos importantes, como idade, grau de letramento, grau de instrução dos familiares, condições socioeconômicas etc. Planejamos a partir do pouco que sabíamos delas, dividindo as ações em duas unidades didáticas: Meu corpo, minha casa e Eu, a natureza e a dança. A primeira unidade explora o corpo dos(as) estudantes, das pessoas no seu entorno, e a relação com suas casas; e a segunda busca a relação com o mundo fora de casa. A ideia é que "[...] as crianças percebam que seus corpos também são articulados e conectados ao mundo, à sociedade, às pessoas [...], de que somos parte e todo da sociedade ao mesmo tempo." (MARQUES, 2012, p. 100). Por causa das condições de internet, não tivemos possibilidade de encontros síncronos em que pudéssemos aprofundar o diagnóstico das turmas de crianças.

No caso das professoras, fizemos um pré-planejamento antes do primeiro encontro, apontando os conteúdos que considerávamos importantes, e no qual elas 


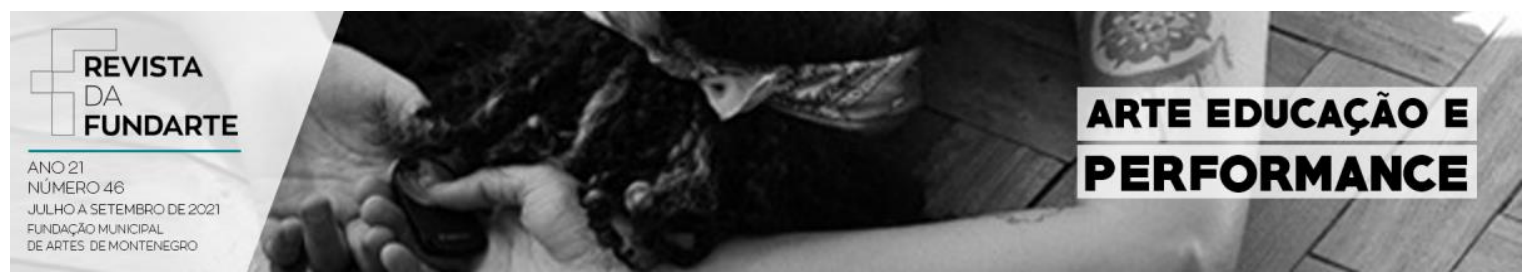

puderam se apresentar e conversarmos. Para elas, planejamos sete aulas, com os seguintes conteúdos: Criança como performer, Corpo, Espaço e Criação. No entanto, durante o semestre, de acordo com compromissos da escola, conseguimos realizar seis aulas/encontros formativos, o que provocou a condensação de alguns conteúdos. Os encontros formativos da ação (Edu)dançando seguiam a seguinte dinâmica: envio de um texto na semana anterior e chegada à temática da aula por meio de atividades práticas. No final, debates sobre o encontro e sobre as leituras assíncronas.

Tanto com as crianças quanto com as professoras, começamos nossas investigações de movimento a partir de seus nomes e seus reconhecimentos corporais.

As primeiras quatro atividades da ação Crian(dan)ça e seus respectivos vídeos foram gravados antes do contato com a turma, uma vez que a gravação e a edição demandam tempo e não gostaríamos de ter o prazo de entrega sem os mesmos prontos - enviávamos uma vez por semana. Os vídeos/atividades de dança tinham no máximo cinco minutos e apresentavam uma explicação sobre a proposta do dia. Nossas atividades eram planejadas como uma brincadeira dançante, com exploração de movimentos e, às vezes, narrativas e histórias. Além disso, quase toda a primeira unidade estava planejada antes do projeto começar. Com o tempo, à medida que tínhamos feedback, fomos revendo as atividades propostas e modos de descrições das mesmas, buscando mais engajamento.

Por sua vez, a ação (Edu)Dançando na Escola começou quase um mês depois de iniciadas as atividades com as crianças. Com encontros quinzenais, algumas formações realizadas articulavam-se aos conteúdos trazidos para os(as) alunos(as) e também debates de textos relacionados à Dança e seu ensino, tais como, o conceito de criança como performer (Machado, 2010), Temáticas de Dança - corpo, fundamentos, criação (Godoy e Andrade, 2018; Marques, 2010), e estruturas para realização de aulas de dança da educação infantil e ensino fundamental anos iniciais e os sentimentos desse corpo em isolamento, além do 


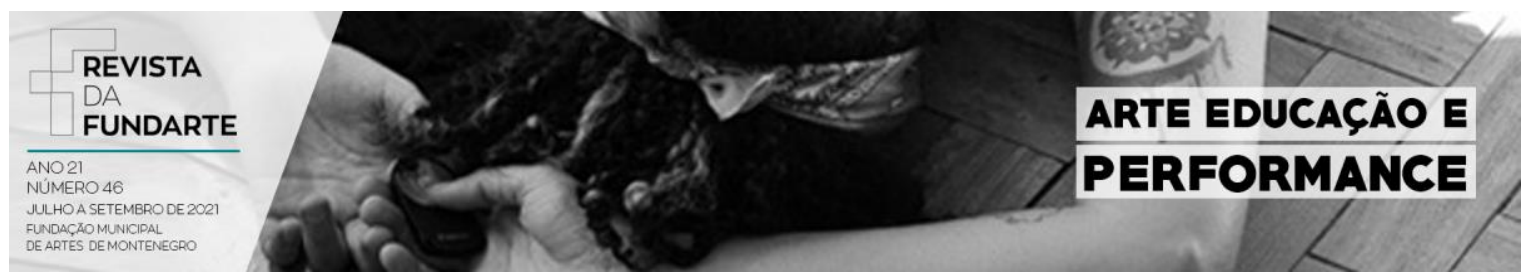

compartilhamento de experiências de ensino-aprendizagem. As leituras, em si, traziam diferentes dicas e inspirações para se pensar a dança na escola, com sugestões de atividades, no entanto, durante esses encontros, a escuta e troca de vivências foram primordiais e enriquecedoras. Era na prática que o conhecimento sobre Dança se corporificava e se tornava conhecimento de Dança.

A última ação do projeto desenvolvida em 2020 foram as lives 5 e 6, que eram abertas à toda a comunidade. Esta ação foi pensada como mais uma atividade de formação continuada das professoras que estavam atuando conosco, mas também como ação formadora para os(as) estudantes do Curso de DançaLicenciatura e demais profissionais da área. Por isso, foram pensadas apenas duas temáticas: dança com crianças e educação antirracista. Primeiro, porque estávamos, na escola em questão, e no projeto de extensão como um todo, trabalhando com crianças; segundo, porque a questão antirracista se faz emergente nas formações continuadas de professores(as) e, em novembro, comemora-se o Mês da Consciência Negra, oportunidade para que as questões do racismo e da negritude são evidenciadas - não que não possam e não devam ser discutidas em outras épocas do ano. Estas lives tinham participação variada de 10 a 20 pessoas por encontro, mas ficaram gravadas, podendo ser acessadas em outros momentos.

\section{Tateando uma dança}

Se a internet nos possibilita a conexão imediata com as pessoas em diversos tempos-espaços, também nos traz desafios, sobretudo em atividades como a Dança, uma arte da presença. Nesse sentido, tivemos muita dificuldade em relação ao feedback, sobretudo no caso das crianças, uma vez que não tínhamos encontros síncronos, devido às dificuldades de conexão de internet. Como nos lembram Miller e Laszlo (2020, p. 98): 


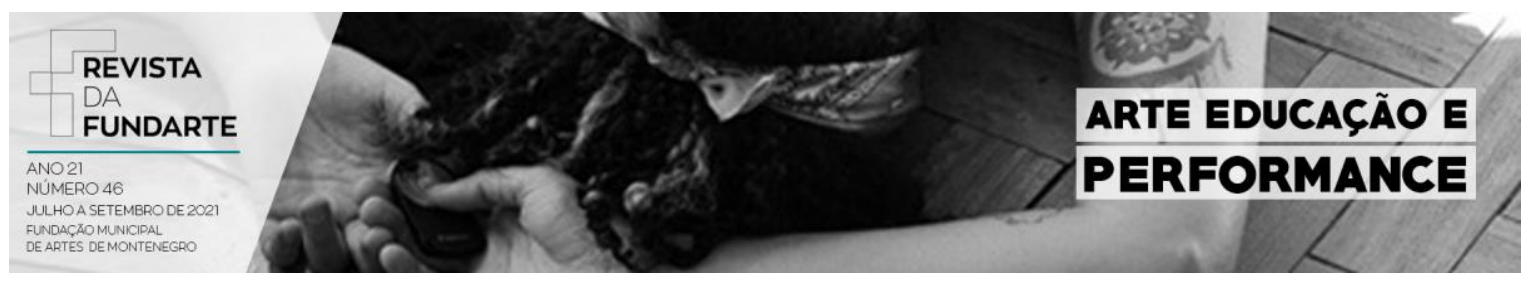

$\mathrm{Na}$ comunicação assíncrona, as interações e trocas acontecem em tempos diferentes, não exigindo a participação em tempo real do docente e discentes. Portanto, podemos dizer que a presença, em tempos de isolamento, está sendo contemplada e ressignificada por atividades remotas síncronas, definida como telepresença, ou seja, a presença permitida através de uma tela.

Como é o feedback assíncrono? No síncrono, é possível ver, on-line, como as pessoas estão entendendo a proposta e, se necessário, intervir no ato. Mas no assíncrono há muitas variáveis. A primeira delas é o envio do feedback, ou seja, que quem está acompanhando os vídeos, as atividades, mande algum tipo de feedback como escritas, áudios ou vídeos para que quem está propondo as atividades tenha dimensão de como estas chegam e se os objetivos estão sendo alcançados. Nas três ações do projeto de extensão, o feedback se deu de formas variadas.

Pelo que percebemos, as crianças não tinham vivenciado aulas ou atividades de Dança - no caso das professoras, algumas tinham algum contato com dança anterior ao projeto. Assim, nosso retorno às ações propostas variava conforme o grupo. No caso das crianças, recebíamos mensagens no grupo de Whatsapp, enquanto em relação às professoras, como os encontros eram síncronos, podíamos ver, no momento, como reagiam às propostas - apesar de que algumas desligavam as câmeras. Nas lives 5 e 6 , os retornos também era no ato, durante a realização das mesmas, com comentários e perguntas no chat.

A partir dos vídeos recebidos no grupo de Whatsapp da ação Crian(dan)ça, percebemos que os(as) estudantes tinham dificuldade em fazer investigações de movimento. Por isso, ao longo do processo, fomos replanejando as atividades, com acréscimo de informações que pudessem auxiliá-los(as) a melhor compreender o que estávamos propondo. Para termos mais feedback, uma estratégia proposta foi deixar um espaço para que a criança desenhasse, na atividade impressa, o que sentiu ao realizá-la. Somente uma vez tivemos, por parte das professoras, retorno sobre esses desenhos. Ao longo do semestre criamos outras estratégias, como propor que gravassem um vídeo e convidassem um(a) colega para fazer o mesmo. 


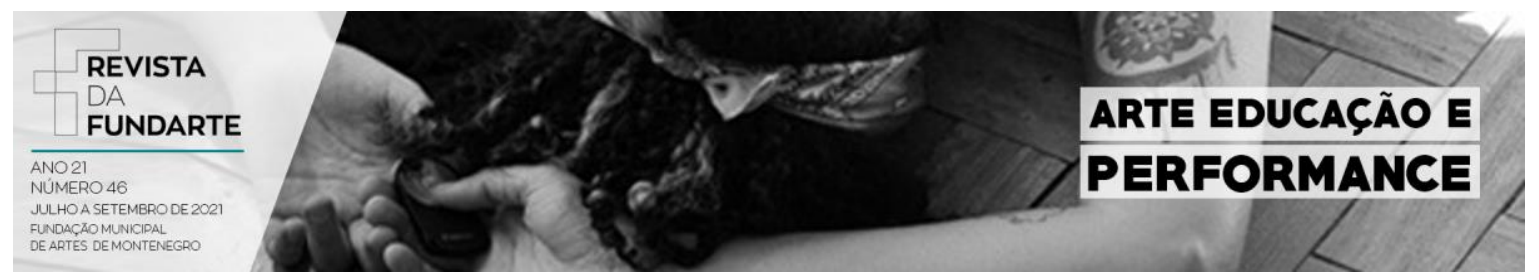

Semanalmente nos reuníamos, avaliávamos os vídeos e replanejávamos as atividades tanto da ação Crian(dan)ça quanto da (Edu)Dançando na Escola. No caso das lives, estas foram todas planejadas no final de setembro e início de outubro, com sua programação. Uma percepção nossa foi a de que algumas movimentações das crianças eram iguais às dos vídeos, ou eram fragmentadas e com poses. Tínhamos a sensação, muitas vezes, que não estavam investigando, mas apenas cumprindo uma tarefa da escola. Tentávamos, então, no vídeo - e na escrita - falar da atividade como uma brincadeira, de propor que fizessem de várias formas. Por sua vez, na ação com as professoras, as movimentações eram sempre espontâneas, mesmo sendo simples, a identidade de cada professora era nítida na movimentação. O espaço físico que possuíam durante nossos encontros não parecia totalmente favorável à exploração, mas investigavam das formas que podiam. Notamos que algumas realizavam movimentação mais elaborada, pensada e precisa.

O conteúdo que destacamos ao trabalhar com as professoras foram fundamentos da dança - corpo e espaço -, discutindo a partir de Isabel Marques (2010) e Katia Godoy e Carolina Andrade (2018), pois sabemos que na escola a ideia das cadeiras e classes infelizmente resume o ambiente de ensino, e ao sair dessa zona de conforto, desafiamos as professoras a reconhecerem a si, e às suas práticas docentes, talvez levando a um reencontro com a professoralidade de cada uma, trocando experiências e vivenciando a Dança na educação e a educação na Dança.

Ao longo do processo, na ação Crian(dan)ça, insistimos na fala de que, se quisessem - ou seja, não eram obrigados(as) - mandassem um vídeo com o que mais tinham gostado da exploração, e, a partir da segunda unidade, passamos a incentivar que convidassem um(a) colega na gravação. Se no início nosso planejamento foi bastante antecipado, com descrições e vídeos prontos em aproximadamente três ou quatro aulas antes do envio, ao longo do processo mudamos, tentando 'escutar' os(as) estudantes e seus poucos feedbacks. Então 


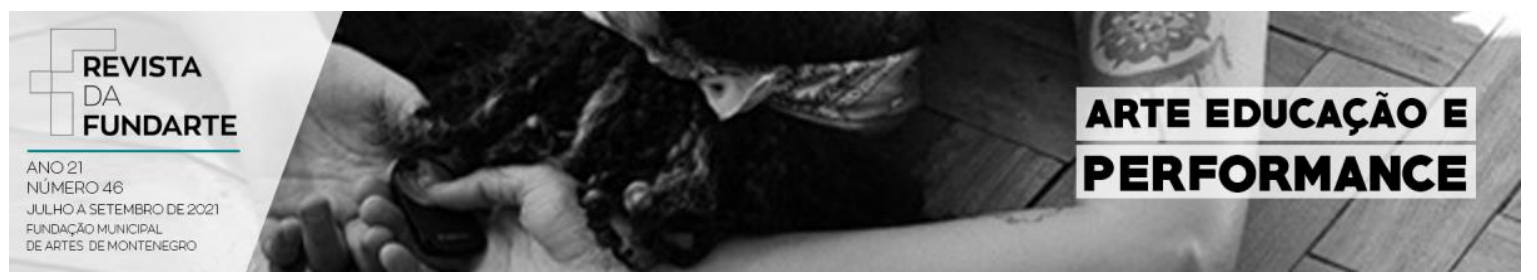

mais vídeos surgiram entre as semanas, modificações das descrições e diferentes formas de envio, como o acréscimo da mensagem por áudio.

Como avaliação da atividade do (Edu)dançando na escola, muitas reflexões surgiram sobre temas como novos olhares para a infância através do movimento, da Dança, trazendo descobertas próprias e também do corpo do(a) outro(a), mostrando as potências de transcender as aulas para além do papel, da sala de aula tradicional. Pensamentos sobre olhar a partir do olhar da criança trouxeram às docentes a vontade de deixar um pouco de lado os conteúdos rígidos, e integrar desde os anos iniciais, a dança e seus conteúdos, desenvolvendo assim o ensinoaprendizagem juntamente com as descobertas do corpo de cada um, de si. Em suas falas, durante os encontros, e na avaliação final do projeto, muitas relataram o fato de não terem ao longo de suas formações atividades/conteúdos ligados ao corpo sensível, à estética e ao movimento dançado.

Já as lives 5 e 6 foram programadas no final de setembro, pensadas como mais uma ação de formação continuada. Assim, foram convidadas duas pessoas para falarem sobre dança com crianças em outubro - porque estávamos trabalhando com este público na escola, mas também porque é o mês das crianças - e três pessoas para falarem, em novembro, sobre uma educação antirracista. Em cada uma das lives, a pessoa convidada falava sobre sua metodologia de ensino a respeito do tema e como havia adaptado ou não seu trabalho ao ensino remoto, durante a pandemia. Além disso, ao longo da live, a apresentadora fazia perguntas aos convidados e convidadas, assim como lia questões escritas no chat. A participação nas lives variou conforme o dia e o(a) convidado(a), com presença tanto de professores(as) da educação básica quanto de estudantes de licenciatura em Dança de diversas regiões do país.

\section{Conclusões}

Talvez a grande problemática do ensino remoto seja a questão da interação. Quando há encontros síncronos, há maior interação. Pessanha e Macedo (2020, p. 


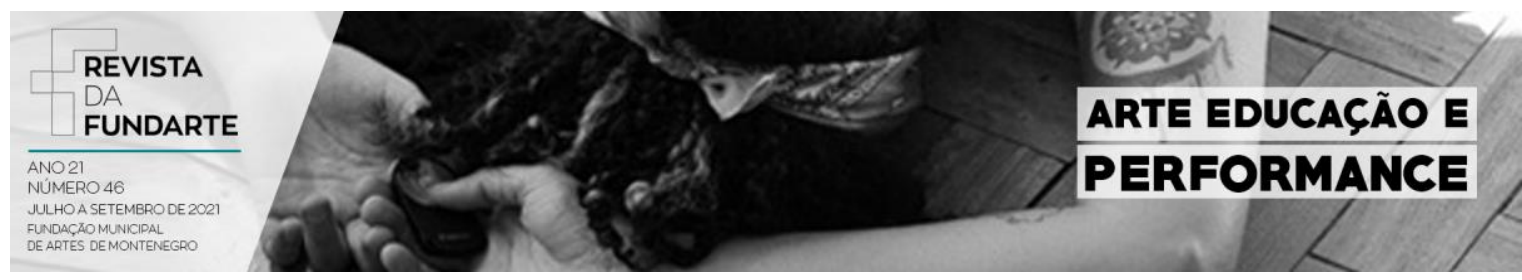

352) dizem que a escola é o lugar onde as crianças se encontram com seus iguais, com suas singularidades e diferenças e que o ensino remoto provoca limitações, principalmente "[...] sócioafetivas, inerentes aos aparatos tecnológicos de virtualização que despotencializam as trocas nas relações presenciais entre as crianças [...], o que compromete a interação."

Na presencialidade, os(as) colegas, os afetos são importantes fatores que nos atravessam e que interferem em nossas criações, investigações e aprendizados. Além disso, no presencial, os(as) professores(as) podem intervir ao longo das explorações, indicando outras formas.

Com as três ações do projeto de forma remota, podemos inferir que as atividades assíncronas tendem a ser realizadas como tarefas, sem interação, o que demanda de nós, professores(as) mais investigação metodológica. Ou seja, na média, elas não favorecem a interação e o feedback.

Ao final do projeto, compreendemos que, mesmo com as dificuldades relativas à internet, é importante o contato síncrono, para criação de vínculos e interferência docente, mesmo que este ocorra em um espaçamento maior. Percebemos que as dificuldades do contexto da escola pública nos possibilitam ter que buscar estratégias diferenciadas e foi o que fizemos ao longo do processo. Não criamos fórmulas de danças no ensino remoto, mas sabemos que fizemos as danças possíveis para o momento e que, em outra oportunidade, estaremos com um acervo de possibilidades maiores. Assim, aprendemos com o vivenciado.

Outro fator importante é que, sempre que planejamos uma aula, nos perguntamos para quem ela será oferecida, em qual contexto, quais objetivos. E as professoras e turminhas que fomos conhecendo aos poucos foram nos trazendo essas pistas, pois éramos novas para elas e elas, novas para nós. Neste sentido, verificamos, ao longo do processo, a necessidade de, mesmo com o ensino remoto, ter a oportunidade e criar estratégias para fazer um melhor diagnóstico. Acreditamos que a dificuldade de conhecer o público - por parte das crianças -, possa ter sido um fator do difícil feedback. 


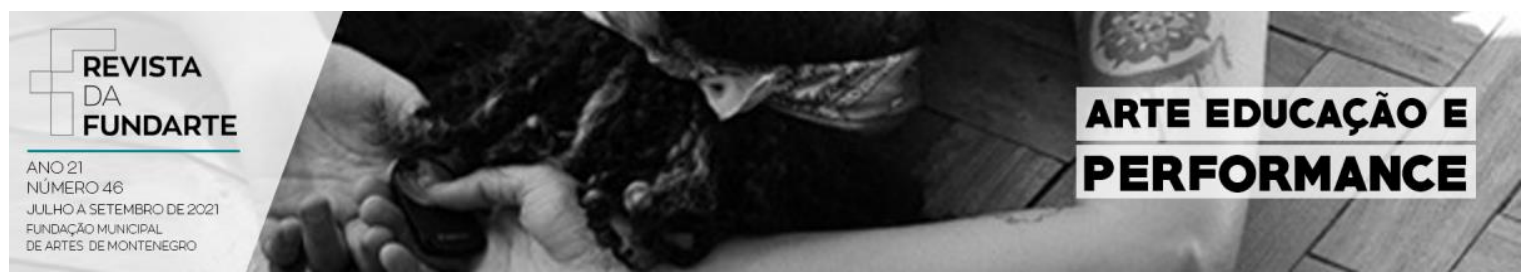

No caso das professoras, os feedbacks nos fazem concluir a importância da formação continuada e da formação em Dança - inclusive da inserção desta disciplina nas suas formações iniciais. Ouvimos das professoras, durante os encontros de formação e avaliação do mesmo, que ao terem tido essas experiências de estudos com o corpo, fundamentos da dança e criação, perceberam que tinham perdido a fantasia, magia da infância. Ou seja, o curso the possibilitou este reencontro com o lúdico, com a estética etc. Assim, juntamente refletimos em quais momentos de nossas vidas e como essas sensações, infelizmente, vão sumindo, e como trazê-las novamente em nosso dia-a-dia pessoal e profissional com nossos alunos e alunas.

Acreditamos que elas perceberam o potencial da Dança em suas aulas e podem ser grandes aliadas para a inserção da Dança, de fato, na escola. O que queremos dizer é que, do ponto de vista legal, nós, professoras de Dança, atuamos apenas em duas etapas da educação básica: ensino fundamental II e ensino médio, e, nas etapas anteriores, quem atua são os(as) pedagogos(as) - são raras as escolas que têm especialistas nestas etapas. Assim, quando estes(as) profissionais compreendem o papel da Dança na educação, podem lutar conosco para a inserção da Dança na escola ou introduzirem, em suas aulas, questões de Dança. Na nossa avaliação, isto, inclusive pode nos ajudar quando entrarmos nas etapas posteriores - uma vez que o preconceito com a Dança cresce nas etapas finais da educação básica. 


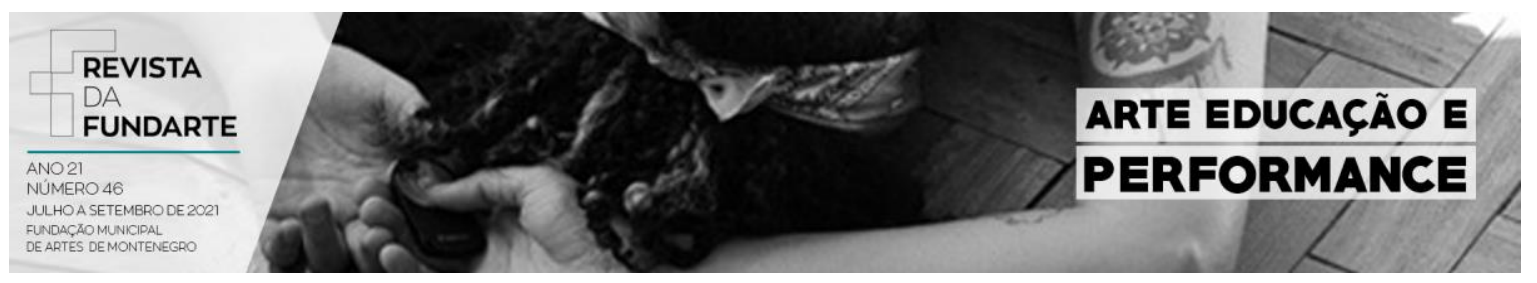

\section{Referências:}

ANDRADE, Carolina Romano de. GODOY, Kátia Maria Ayres de. Dança com crianças. Curitiba: Appris, 2018.

BARBOSA, Larissa Ferreira Regis. Dança transmídia: as táticas de corpo composto. 2016. 396 Fls. Tese (Doutorado em Arte). Universidade de Brasília, Brasília, 2016.

FLORES, Natália. Desigualdade social e tecnologia: o ensino remoto serve para quem? Covid-19, Unicamp, 2020. Disponível: https://www.blogs.unicamp.br/covid19/desigualdade-social-e-tecnologia-o-ensino-remoto-serve-para-quem/ Acesso: 19 jan 2021

MARQUES, Isabel. Interações: criança, dança e escola. São Paulo: Blucher, 2012. . Linguagem da dança: arte e ensino. São Paulo: Digitexto, 2010.

MACHADO, Marina Marcondes. A criança é performer. Educação e Realidade. Porto Alegre: UFRGS, 35(2), mai-ago 2010a p. 115-137

MILLER, Jussara.; LASZLO, Cora Miller. Corpos em conexão, corpos em presença. Manzuá: Revista de Pesquisa em Artes Cênicas, v. 3, n. 2, p. 95-116, 24 nov. 2020. Disponível em: < https://periodicos.ufrn.br/manzua/article/view/23207>. Acesso: 1 dez. 2020

NICOLINI, Fernanda de Oliveira Nicolini. Telematismo: uma vacina para corpos pandêmicos que dançam. Rebento, São Paulo, n. 12, p. 292-310, jan - jun 2020. Disponível: <http://www.periodicos.ia.unesp.br/index.php/rebento/article/view/464> Acesso: 18 jan 2021

PESSANHA, Fabiana. MACEDO, Nayara Alves. Educação da pequena infância: (Re)pensando limites e possibilidades diante de algumas inflexões impostas pela pandemia da Covid-19. Revista Interinstitucional Artes de Educar. Rio de Janeiro, V. 6 - N. Especial - pág. 339 - 359 - (jun. - out. 2020): "Educação e Democracia em Tempos de Pandemia". Disponível em: < https://www.epublicacoes.uerj.br/index.php/riae/article/view/52291> Acesso: 19 nov. 2020

RACHEL, Denise Pereira; MARQUES, Diego Alves; MARIANO, Bárbara Kanashiro. Artivismo respiratório: Uma Proposta de Educação Remota no país irrespirável. Revista Manzuá, 2020, v. 3, n. 2, p.7-34. Disponível em: <https://periodicos.ufrn.br/manzua/article/view/22725> Acesso: 1 dez. 2020

SANTANA, Ivani. Dança na cultura digital. Salvador: EDUFBA, 2006. 


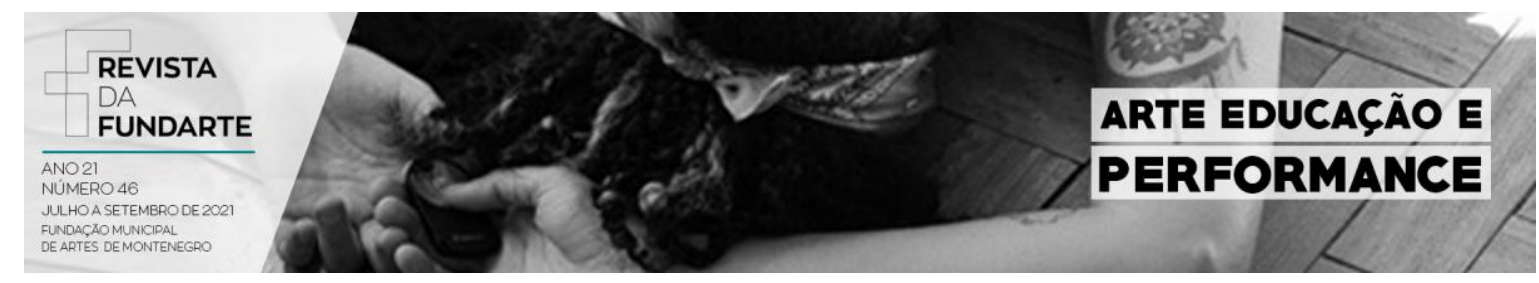

SPODE, Pedro Leonardo Cezar; RIZZATTI, Maurício; ROCHA, Lilian Hahn Mariano da; FARIA, Rivaldo Mauro de; COSTA, lago Turba. Pobreza e seletividade espacial no bairro universitário Camobi, Santa Maria, RS: uma análise a partir dos usos do território. Geografia Ensino e Pesquisa, V. 23, 2019. Disponível: <https://periodicos.ufsm.br/geografia/article/view/40108/html> Acesso: 18 jan 2020 